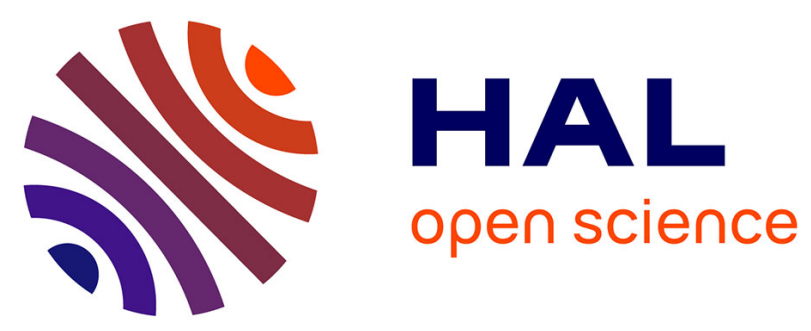

\title{
Comparative experimental study of junctionless and inversion-mode nanowire transistors for analog applications
}

Daphnée Bosch, J.P. Colinge, J. Lugo, A. Tataridou, Christoforos Theodorou, X. Garros, S. Barraud, J. Lacord, B. Sklenard, M. Casse, et al.

\section{To cite this version:}

Daphnée Bosch, J.P. Colinge, J. Lugo, A. Tataridou, Christoforos Theodorou, et al.. Comparative experimental study of junctionless and inversion-mode nanowire transistors for analog applications. 2020 International Symposium on VLSI Technology, Systems and Applications (VLSI-TSA), Aug 2020, Hsinchu, Taiwan. pp.126-127, 10.1109/VLSI-TSA48913.2020.9203690 . hal-02969748

\section{HAL Id: hal-02969748 https://hal.science/hal-02969748}

Submitted on 27 Dec 2020

HAL is a multi-disciplinary open access archive for the deposit and dissemination of scientific research documents, whether they are published or not. The documents may come from teaching and research institutions in France or abroad, or from public or private research centers.
L'archive ouverte pluridisciplinaire HAL, est destinée au dépôt et à la diffusion de documents scientifiques de niveau recherche, publiés ou non, émanant des établissements d'enseignement et de recherche français ou étrangers, des laboratoires publics ou privés. 


\section{Comparative experimental study of junctionless and inversion- mode nanowire transistors for analog applications}

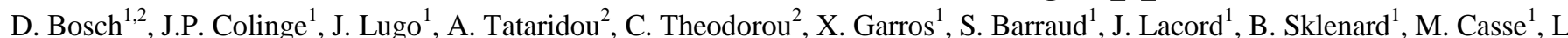
Brunet $^{1}$, P. Batude ${ }^{1}$, C. Fenouillet-Béranger ${ }^{1}$, D. Lattard ${ }^{1}$, J. Cluzel ${ }^{1}$, F. Allain ${ }^{1}$, R. Nait Youcef ${ }^{1}$, J.M. Hartmann ${ }^{1}$, C. Vizioz ${ }^{1}$, G.

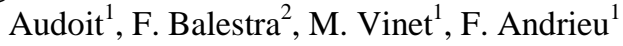

${ }^{1}$ CEA-LETI, Univ. Grenoble Alpes, 17 rue des Martyrs, 38054 Grenoble, France ; email: daphnee.bosch@cea.fr ${ }^{2}$ Univ. Grenoble Alpes, IMEP-LAHC, 38000 Grenoble, France

| Abstract - We fabricated JunctionLess (JL) and Inversion-Mode (IM) monocrystalline nanowire NMOSFETs down to $\mathrm{L}=18 \mathrm{~nm}$ gate length and $\mathrm{W}=20 \mathrm{~nm}$ width. We demonstrate record performance of nanowire junctionless transistors for analog applications: $\mathrm{A}_{\mathrm{VT}}=1.4 \mathrm{mV} . \mu \mathrm{m}$ matching, $\mathrm{Av} 0=62 \mathrm{~dB}$ gain $(\mathrm{L}=200 \mathrm{~nm}), \mathrm{f}_{\mathrm{T}}=126 \mathrm{GHz}$ cut-off frequency and $\mathrm{f}_{\mathrm{MAX}}=182 \mathrm{GHz}$ maximum operating frequency. Junctionless transistor performances even exceed those of IM-FETs in terms of back-bias capability, low-frequency noise, hot-carrier degradation and $\mathrm{f}_{\mathrm{MAX}}$. This is explained by JL physics combining characterization and TCAD simulations: channel length modulation, bulk conduction and high channel depth sensitivity to back bias.

\section{INTRODUCTION}

Recent years have seen renewed interest for JL CMOS transistors because of the relative simplicity of its process integration and its potential fabrication at low temperature as a Back-End-Of-Line transistor for a 3D-sequential integration [1]. On the one hand, polycrystalline silicon or germanium channels, whose doping is activated by a laser anneal, are a promising solution for low-cost and extremelylow-temperature fabrication [2,3]. On the other hand, monocrystalline $\mathrm{Si}$ junctionless channels have already been demonstrated on either planar Silicon-On-Insulator (SOI) [4], FinFET [5] or nanowire architectures [6,7]. Furthermore, JL devices are attractive for analog applications since they are less prone to Hot Carrier Injection (HCI).

\section{DEVICE PROCESS FLOW}

We fabricated IM and JL nanowire nMOS down to $\mathrm{W}=20 \mathrm{~nm}$ channel width and $\mathrm{L}=18 \mathrm{~nm}$ gate length. The channel thickness is $11 \mathrm{~nm}$. The junctionless devices are made by epitaxially growing a $7 \mathrm{~nm}$ thick in-situ phosphorous (P) doped Si film on a $4 \mathrm{~nm}$ undoped SOI layer. Excellent crystalline quality is obtained (Fig.1). After full process integration the final channel doping level is uniform and equal to $10^{19} \mathrm{at} / \mathrm{cm}^{3}$. Such channel doping and thickness are optimized for planar devices. The fabrication process is outlined in Fig.2. All the devices feature the same gate stack with $\mathrm{HfO}_{2}$ dielectrics (equivalent oxide thickness EOT=1nm), TiN + poly-Si and identical $8 \mathrm{~nm}$ thick spacer.

In order to assess the impact of the channel doping and the source/drain resistance, we added the same $17 \mathrm{~nm}$ thick Raised Souce/Drain (RSD) and HDD+LDD doping processes for so-called Junctionless Accumulation Mode (JAM) transistors as for the IM reference (final anneal at $1050^{\circ} \mathrm{C}$ ). Purely Junctionless transistors (named JL) have also been fabricated without doping under the spacer. Instead, a $5 \mathrm{keV} \mathrm{P}$ implantation in the $17 \mathrm{~nm}$ thick RSD followed by a Solid Phase Epitaxy Regrowth (SPER) annealing at $525^{\circ} \mathrm{C} 30$ min was carried out, in order to only dope the JL-RSD (see Kinetic MonteCarlo profile on Fig.2) and avoid lateral doping diffusion. This process module is suitable for a $525^{\circ} \mathrm{C} 3 \mathrm{D}$-sequential integration process [8].

III. DEVICE ELECTRICAL CHARACTERIZATION

Digital $\mathrm{I}_{\mathrm{ON}}-\mathrm{I}_{\mathrm{OFF}}$ figure of merit (Fig 3) show no significant difference between JAM and IM FET. Also, similar parasitic gate to SD capacitance $\mathrm{C}_{\mathrm{GDS}}$ suggests a similar direct overlap controlled by the SD implant (Fig. 4). On the other hand, the JL FET has a $0.06 \mathrm{fF} / \mu \mathrm{m}$ lower $\mathrm{C}_{\mathrm{GDS}}$ vs JAM/IM, which cannot be explained by the fringe components but rather by a depletion region extending below the spacers in JL transistors (Fig.5). Nevertheless JL devices suffers from higher access resistance $\left(\mathrm{R}_{0}\right)$ due to non-optimized junctions (Fig 3).
Local variability: matching coefficient $A_{V T}$ is higher for JL/JAM devices than IM (1.7/1.4 vs. $1.0 \mathrm{mV}$. $\mu \mathrm{m}$, Fig. 6$)$. This degradation with the channel doping is attributed to Random Dopant Fluctuation [9].

Analog: we consider a nominal transistor width of $\mathrm{W}=0.24 \mu \mathrm{m}$, (planar SOI configuration instead of a trigate nanowire structure). The JL/JAM subthreshold slope (SS) is $\mathrm{SS}=64 \mathrm{mV} / \mathrm{dec} v s .61 \mathrm{mV} / \mathrm{dec}$ for the IM device (Fig. 7). However, back-bias can be leveraged in order to adjust the threshold voltage and tune performance [10]. Indeed, back-bias is more effective for wider than for narrower devices and it is more effective on JL/JAM than on IM transistors (Fig.8). Markedly, a negative back-bias applied on JAM moves the bulk conduction channel upwards towards the gate, which results in an improvement of the electrostatic control (SS, $\mathrm{g}_{\mathrm{d}}$ ) and, therefore, improving $\mathrm{g}_{\mathrm{m}} / \mathrm{I}_{\mathrm{d}}$ and $\mathrm{g}_{\mathrm{m}} / \mathrm{g}_{\mathrm{d}}$, as well as the Early voltage $\left(\mathrm{V}_{\mathrm{EA}}\right)$ (Figs $\left.9-10\right)$. As a result, JAM FETs reach analog performances that are slightly better than IM devices, up to an $A_{v 0}=68 \mathrm{~dB}$ gain.

Reliability: we have performed Positive Bias Temperature Instability (PBTI) and Hot Carrier Injection (HCI) (Figs. 11-12). We demonstrate similar PBTI ( 88 years lifetime at $\mathrm{V}_{\mathrm{DD}}=0.8 \mathrm{~V}$ ) and even better $\mathrm{HCI}$ for JL as compared to IM. It can be explain by a lower and shifted to the drain (not underneath the gate dielectric as for IM/JAM) peak electric field.

Low-frequency drain current noise measurements (Fig.13) show a 31-die average $1 / f$ signature and a slightly lower input-referred gate voltage noise level $\left(\mathrm{S}_{\mathrm{Vg}}\right)$ for JAM. Using the Carrier number fluctuations with Correlated Mobility Fluctuations model [11] and taking into account the series resistance noise $\left(\mathrm{S}_{\mathrm{Rsd}}\right)$, we fitted the normalized drain current noise at $\mathrm{f}=10 \mathrm{~Hz}$ (Fig.28) to extract the volumetric oxide effective trap density $\mathrm{N}_{\mathrm{T}}$, and the remote Coulomb scattering coefficient $\alpha_{\mathrm{sc}}$ for all wafers. We extracted a value of $\mathrm{N}_{\mathrm{T}} \approx$ $7.510^{17} \mathrm{eV} / \mathrm{cm}^{3}$ for all cases, reflecting a similar interface quality, independently of the conduction mode. This value is also very close to state-of-the-art $\mathrm{N}_{\mathrm{T}}$ values of high-k-metal-gate CMOS technologies [12]. Concerning $\alpha_{\text {sc }}$, a very similar value $\left(\approx 4 \times 10^{3} \mathrm{Vs} / \mathrm{C}\right)$ is extracted for all wafers, showing that the remote Coulomb scattering is not affected by the different conduction modes. Finally, $S_{\text {Rsd }}$ has a significant impact only for JL, which can be linked to non-optimized source/drain doping [13].

Mobility differences, due to channel doping, are also translated into a cut-off frequency shift, measured at $\mathrm{F}_{\mathrm{T}}=130 \mathrm{GHz}$ for JAM vs. $136 \mathrm{GHz}$ for IM. But JAM exceeds IM devices in terms of $\mathrm{F}_{\text {MAX }}$ because of lower gate capacitances $\mathrm{C}_{\mathrm{GDS}}$. We demonstrate a record $\mathrm{F}_{\max }=182 \mathrm{GHz}$ for JAM nMOS (Fig 15).

\section{CONCLUSION}

Finally, our devices feature record performance among junctionless nMOSFETs (Fig.16). Thanks to process technology variants, electrical characterizations and TCAD simulations, we demonstrated that such a technology offers a good tradeoff for mixed analog/digital applications.

\section{REFERENCES}

[1]A. Vandooren et al., TED, 2018. [2]J. Lin et al., EDL, 39, 9, p. 1326-29, 2018. [3]D. Bosch et al., S3S, 2019. [4]C. Lee et al., TED, 2010. [5]T. K. Kim et al., EDL, 2013. [6]A. Veloso et al., VLSI, 2016. [7]S. Barraud et al, EDL, 2012 [8]J. Micout et al., S3S, 2017. [9] A. Kranti et al., ESSDERC, 2010 [10]R. Trevisoli et al., EUROSOI, 2015. [11] G. Ghibaudo et al., PSS,91. [12] E.G. Ioannidis et al., SSE, 2014. [13] C. Diaz-Llorente et al., S3S, 2018 [14]A. Vandooren et al., VLSI, 2018. 


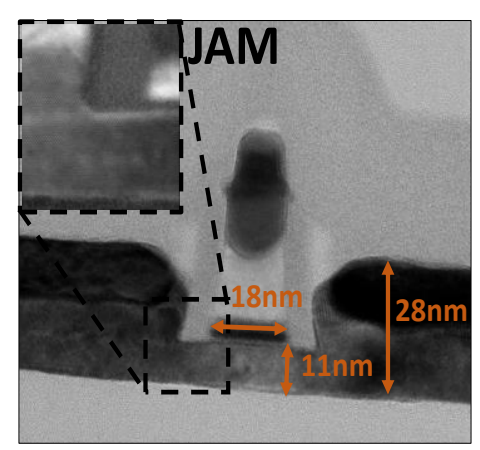

Fig.1: TEM cross section of JAM device. Excellent crystalline quality is observed.

JL

(TCAD)

$$
\text { (TCA }
$$
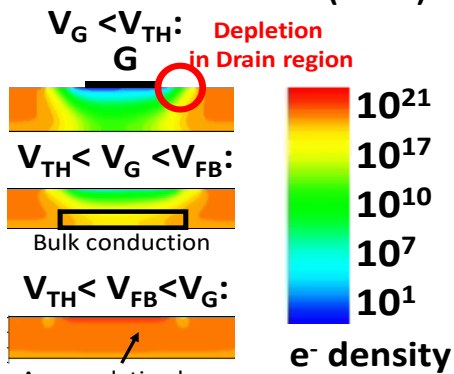

$\left(\mathrm{cm}^{-3}\right)$

Fig. 5 : Electron density (SD cut) highlighting three operation regimes

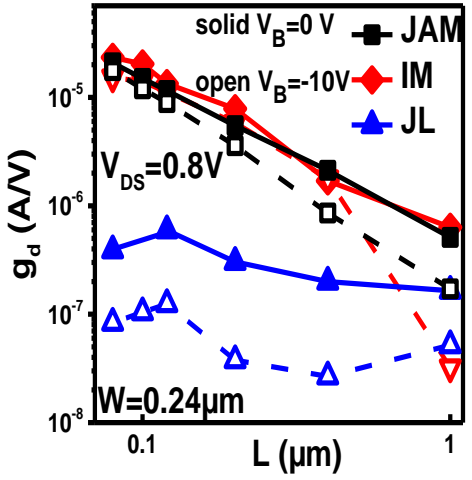

Fig.9: $\mathrm{g}_{\mathrm{d}} v s$. $\mathrm{L}$ for $\mathrm{V}_{\mathrm{B}}=0$ and $\mathrm{V}_{\mathrm{B}}=-$

$10 \mathrm{~V} . \mathrm{V}_{\mathrm{B}}<0$ improves electrostatics.

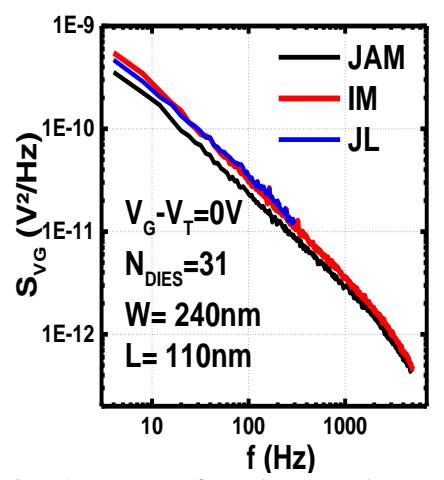

Fig.13: Input-referred gate voltage power spectral density versus frequency

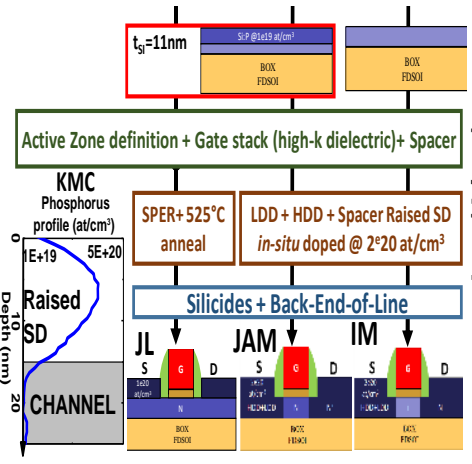

Fig. 2: Detailed Process flow for IM $(\mathrm{N}+-\mathrm{i}-\mathrm{N}+), \mathrm{JAM}(\mathrm{N}+-\mathrm{N}-\mathrm{N}+)$ and JL (N) devices.

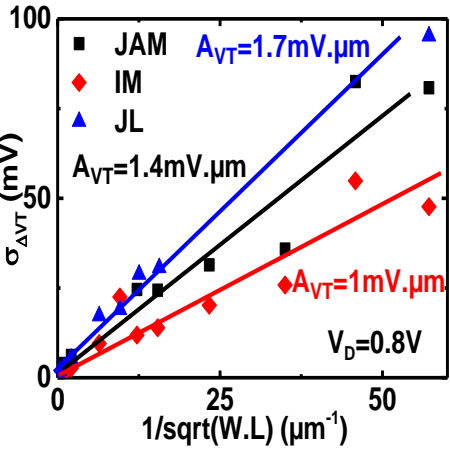

Fig.6: Pelgrom plot (local variability)

\begin{tabular}{|c|c|c|c|c|}
\hline $\begin{array}{c}\text { Gain } \\
\mathbf{A}_{\mathbf{v o}}(\mathbf{d b})\end{array}$ & $\begin{array}{c}\mathbf{V}_{\mathbf{B}} \\
\mathbf{( V )}\end{array}$ & $\begin{array}{c}\mathbf{L}=\mathbf{1 0 0} \\
\mathbf{n m}\end{array}$ & $\begin{array}{c}\mathbf{L}=\mathbf{2 0 0} \\
\mathbf{n m}\end{array}$ & $\begin{array}{c}\mathbf{L}=\mathbf{4 0 0} \\
\mathbf{n m}\end{array}$ \\
\hline \multirow{2}{*}{$\geqq$} & 0 & 1 & 60 & 50 \\
\cline { 2 - 5 } & -10 & 18 & 65 & 53 \\
\hline \multirow{2}{*}{$\lesssim$} & 0 & 1 & 12 & 51 \\
\cline { 2 - 5 } & -10 & 64.5 & $\mathbf{6 8 . 8}$ & 55 \\
\hline \multirow{2}{*}{$\leftrightharpoons$} & 0 & 59 & 47 & 38 \\
\cline { 2 - 5 } & -10 & 61.5 & $\mathbf{6 5}$ & 41 \\
\hline
\end{tabular}

Fig.10: Gain $A_{v 0}$ for different Gate length $\mathrm{V}_{\mathrm{B}}<0$ improves $A_{\mathrm{v} 0}$

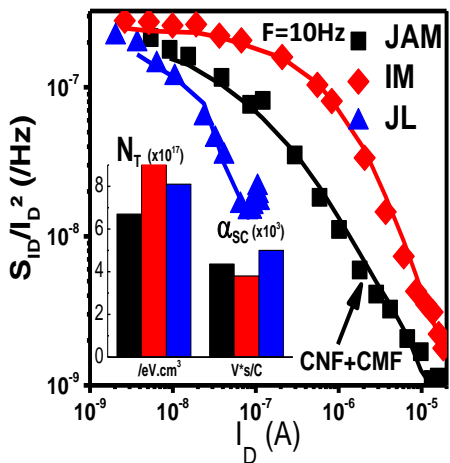

Fig.14: Normalized drain current power spectral density versus $I_{D}$. Inset: Extracted values of $\mathrm{N}_{t}$ and $\alpha_{\mathrm{sc}}$



Fig. 3: $\mathrm{I}_{\mathrm{ON}}-\mathrm{I}_{\mathrm{OFF}}$ for $\mathrm{L}=35 \mathrm{~nm}$ and $\mathrm{W}=20 \mathrm{~nm}$.

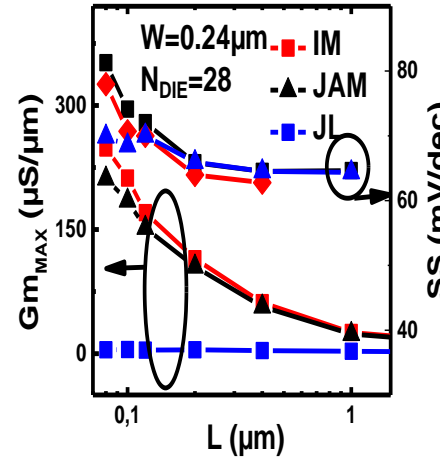

Fig.7: $g_{\operatorname{mMAx}}$ and $\mathrm{SS}$ as a function of $\mathrm{L}$ for $\mathrm{W}=0.24 \mu \mathrm{m}$

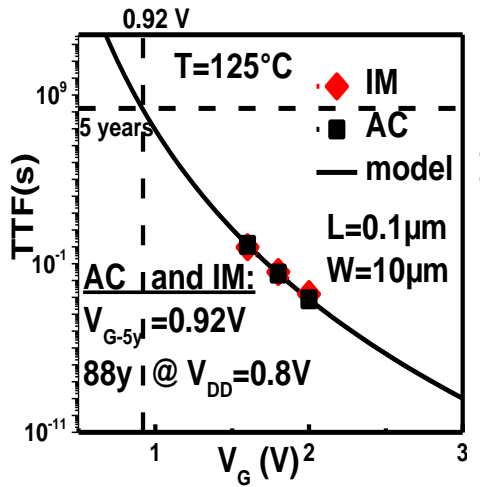

Fig.11: Time-To-Failure for PBTI. The 5-year criterion is met

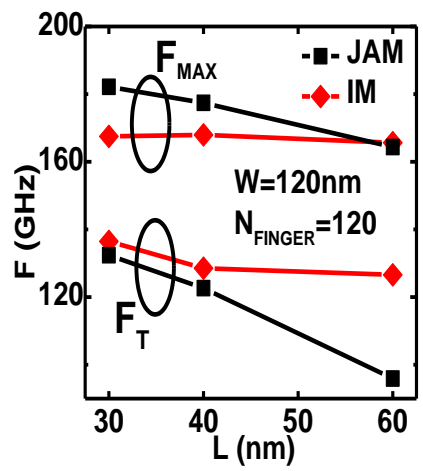

Fig.15: $f_{\text {MAX }}$ and $f_{T}$ comparison for different $\mathrm{L}$.

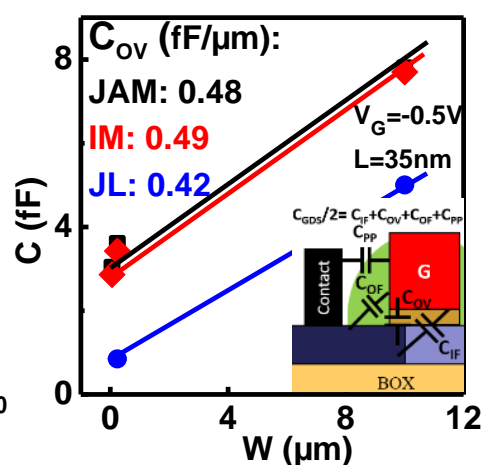

Fig.4: $\mathrm{C}(\mathrm{W})$ and $\mathrm{C}_{\mathrm{GDS}}$ extraction at $\mathrm{L}=35 \mathrm{~nm}$. Inset: Schematic with parasitic capacitance contributions.

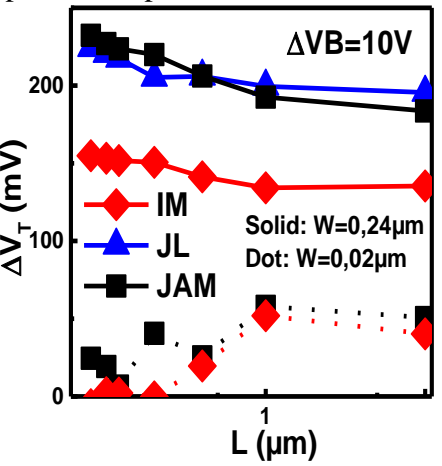

Fig.8: Back bias efficiency for $\mathrm{W}=0.02 \mu \mathrm{m}$ and $\mathrm{W}=0.24 \mu \mathrm{m}$.

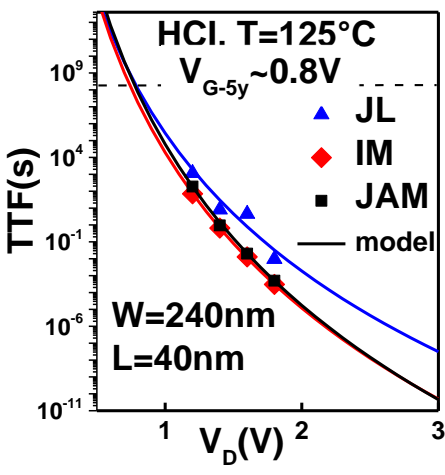

Fig.12: Time-To-Failure for HCI.

The 5-year criterion is met.

\begin{tabular}{|c|c|c|c|}
\hline Ref. & [14] & [6] & $\begin{array}{l}\text { This } \\
\text { Work }\end{array}$ \\
\hline Techno & $\begin{array}{c}\text { Low-Temp } \\
\text { FDSOI }\end{array}$ & NW & $\begin{array}{c}\text { NW/FDS } \\
\text { OI }\end{array}$ \\
\hline $\mathrm{L}_{\mathrm{G}}(\mathrm{nm})$ & 80 & 48 & 35 \\
\hline $\mathrm{V}_{\mathrm{DD}}(\mathrm{V})$ & 1.0 & 1.0 & 0.8 \\
\hline $\begin{array}{c}A_{V T} \\
(\mathrm{mV} \cdot \mu \mathrm{m})\end{array}$ & - & 4.4 & 1.4 \\
\hline$A_{v 0}(d B)$ & $\begin{array}{c}55 \text { for } \\
L=40 \mathrm{~nm}\end{array}$ & $\begin{array}{c}45 \text { for } \\
L=80 \mathrm{~nm}\end{array}$ & $\begin{array}{c}68 \text { for } \\
L=0.2 \mu \mathrm{m}\end{array}$ \\
\hline $\mathbf{f}_{\mathrm{T}}(\mathrm{GHz})$ & 80 & $>70$ & 126 \\
\hline$f_{\max }(G H z)$ & 117 & $\sim 90$ & 169 \\
\hline
\end{tabular}

Fig.16: nMOS junctionless benchmark for analog FOM

ACKNOWLEDGMENTS: This work was funded by French Public Authorities through the NANO2022, LabEx Minos ANR-10-LABX-

$55-01 \&$ by the European Research Council (ERC) through My-CUBE project. 
